\title{
Hubungan Antara Self-Compassion dan Efikasi Diri pada Mahasiswa yang Sedang Menyelesaikan Tugas Akhir
}

\author{
Siswati, Frieda Nuzulia Ratna Hadiyati \\ siswatipsi@gmail.com
}

Fakultas Psikologi, Universitas Diponegoro, Semarang, Indonesia

\begin{abstract}
Students as late adolescents often experience unstable physical and emotional conditions due to suffering they endure. It then affects his efficacy. Self-acceptance is necessary when facing suffering and difficult situations in life. This research aims to determine empirically the relationship between self-compassion and self-efficacy among students who are completing their final project. This research employed a quantitative method with correlational design. The measuring tool used in this research was The Self-Compassion Scale consisting of 22 items $(\alpha=0.858)$ and Self-Efficacy Scale with 22 items $(\alpha=0.850)$. The subjects of this research were 110 third-year students on Faculty of Psychology University $Y$, obtained by simple random sampling technique. Data obtained from this research was then analyzed by using simple regression analysis technique. The result showed the correlation coefficient of 0.741 with $p=0.000$ ( $p<0.05$ ), meaning that alternative hypothesis proposed by the researcher was accepted. Determinant coefficient value of self-compassion gave an effective contribution of $54.9 \%$ for self-efficacy variable, while the remaining $45.1 \%$ is affected by other unrevealed factors.
\end{abstract}

\begin{abstract}
Mahasiswa sebagai remaja akhir sering kali mengalami kondisi fisik dan emosi yang tidak stabil dikarenakan penderitaan yang dialaminya. Hal tersebut selanjutnya berdampak pada efikasi dirinya. Penerimaan diri diperlukan ketika menghadapi penderitaan dan situasi sulit dalam kehidupan. Penelitian ini bertujuan untuk mengetahui secara empiris hubungan antara self-compassion dan efikasi diri pada mahasiswa yang sedang menyelesaikan tugas akhir. Penelitian ini menggunakan metode kuantitatif dengan rancangan korelasional. Alat ukur yang digunakan adalah Skala Self-Compassion yang berjumlah 22 butir $(\alpha=0.858)$ dan Skala Efikasi Diri yang berjumlah 22 butir $(\alpha=0.850)$. Subjek penelitian adalah mahasiswa semester 6 Fakultas Psikologi Universitas Y berjumlah 110 orang yang diperoleh melalui teknik simple random sampling. Teknik analisis data yang digunakan yaitu teknik analisis regresi sederhana. Berdasarkan hasil analisis data yang dilakukan diperoleh koefisien korelasi sebesar 0.741 dengan $p=0.000(p<0.05)$. Artinya, hipotesis alternatif yang diajukan peneliti dapat diterima. Nilai koefisien determinan self-compassion memberikan sumbangan efektif sebesar $54.9 \%$ untuk variabel efikasi diri, sedangkan $45.1 \%$ sisanya dipengaruhi oleh faktor-faktor lain yang tidak diungkap dalam penelitian.
\end{abstract}

Kata kunci: efikasi diri; mahasiswa; self-compassion

Received: Sept. 16, 2017 Accepted: November 27, 2017

How to cite: Siswati, \& Hadiyati, F. N. R. (2017).

Hubungan antara self-compassion dan efikasi diri pada mahasiswa yang sedang menyelesaikan tugas akhir. MEDIAPSI, 3(2), 22-28.

doi:http://dx.doi.org/10.21776/ub.mps.2017.003.02.3

\section{Pendahuluan}

Kehidupan remaja merupakan masa kritis dalam hal prestasi dan penyesuaian diri. Masa remaja adalah masa peralihan dalam rentang hidup manusia dari masa kanak-kanak menuju masa dewasa yang terlihat dengan adanya perubahan pada aspek fisik, psikis, dan psikososial (Santrock, 2012). Tekanan sosial dan akademis menuntut remaja untuk memiliki peran yang melibatkan tanggung jawab lebih besar dari sebelumnya. Remaja mulai memandang sesuatu berdasarkan keberhasilan dan kegagalan yang terjadi saat ini dan dampaknya terhadap keberhasilan dan kegagalan di masa yang akan datang 
(Santrock, 2007).

Mahasiswa adalah individu yang tergolong ke dalam kelompok remaja akhir. Hal ini didukung oleh pernyataan Thornburg (dalam Dariyo, 2004) yang menyatakan bahwa individu yang tergolong remaja akhir pada umumnya telah memasuki perguruan tinggi, lulus sekolah menengah atas, atau bahkan sudah bekerja. Remaja akhir adalah individu yang berada pada rentang usia 17 sampai 22 tahun (Ali \& Asrori, 2008). Mahasiswa sebagai remaja akhir memiliki tugas yang harus dilaluinya. Keberhasilan individu dalam menjalankan tugas perkembangan tersebut akan menentukan perkembangan kepribadiannya. Individu yang mampu melakukannya dengan baik akan menimbulkan perasaan percaya diri, berharga, dan optimis. Sebaliknya, individu yang gagal melakukan tugas perkembangannya akan merasa bahwa dirinya tidak mampu, gagal, rendah diri, kecewa, pesimis, dan putus asa. Mahasiswa dengan efikasi diri akan mampu menyadari, menerima, dan mempertanggungjawabkan semua potensi, keahlian, dan keterampilan secara tepat, serta mendorong dirinya untuk berada pada posisi yang tepat di semua situasi (Dariyo, 2004).

Penelitian Chemers, Hu, dan Garcia (2001) menemukan bahwa efikasi diri akademik berhubungan dengan prestasi dan penyesuaian diri. Efikasi diri secara langsung akan mempengaruhi prestasi akademis dan secara tidak langsung akan mempengaruhinya melalui harapan dan persepsi. Hal ini selaras dengan penelitian yang dijelaskan oleh Baron dan Byrne (2004) bahwa terdapat tiga aspek efikasi diri yang menjadi prediktor penting pada tingkah laku individu yaitu efikasi diri akademis yang berhubungan dengan keyakinan individu akan kemampuannya, efikasi diri sosial yang berhubungan dengan keyakinan individu dalam mempertahankan hubungan, serta efikasi diri yang berhubungan dengan kemampuan menolak tekanan teman sebaya dan kegiatan yang berisiko tinggi.

Stipek (dalam Santrock, 2007) menjelaskan bahwa remaja yang memiliki orientasi pada performa, tetapi tidak memiliki keyakinan akan keberhasilannya, dapat mengalami suatu masalah khusus. Individu akan menganggap bahwa kegagalannya tersebut sebagai bukti bahwa dirinya memiliki kemampuan yang rendah. Hal ini berakibat pada ketidakinginan individu untuk mencoba melakukan sesuatu untuk mempertahankan alasan yang lebih diterima oleh dirinya sendiri, sehingga mengalami penurunan dalam hal performa individu. Secara tidak langsung, efikasi diri mempengaruhi pilihan individu terhadap aktivitas-aktivitas yang akan dilakukannya.

Menurut Santrock (2007) individu dengan efikasi diri tinggi akan merasa antusias menghadapi tantangan-tantangan dan cenderung berusaha keras dalam menyelesaikan sesuatu. Hal tersebut berkaitan dengan motivasi dan performa yang dipengaruhi ekspektasi orang tua, guru, dan orang dewasa lain yang ada di sekitar terhadap prestasi yang seharusnya dicapai. Penelitian Widanarti dan Indati (2002) menjelaskan bahwa terdapat hubungan positif yang sangat signifikan antara dukungan sosial keluarga dengan self-efficacy pada remaja. Semakin tinggi dukungan sosial keluarga maka semakin tinggi self-efficacy dan semakin rendah dukungan sosial keluarga maka semakin rendah self-efficacy.

Menurut Alwisol (2009), efikasi diri merupakan penilaian seseorang terhadap kemampuannya dalam melakukan suatu pekerjaan, mencapai tujuan, atau mengatasi 
hambatan. Seseorang bertindak dalam situasi tertentu tergantung pada hubungan timbal balik antara lingkungan dengan kondisi kognitif, khususnya faktor kognitif yang berhubungan dengan keyakinannya bahwa dia mampu atau tidak mampu melakukan suatu pekerjaan. Performa fisik, tugas akademis, dan kemampuan untuk mengatasi kecemasan dan depresi dapat ditingkatkan melalui perasaan yang kuat akan efikasi diri (Baron \& Byrne, 2004).

Dariyo (2004) mengungkapkan sebuah kejadian yang berkaitan dengan efikasi diri yaitu jika individu memiliki bakat, kemampuan, dan keterampilan menyanyi, maka individu tersebut akan mau menampilkan kemampuannya karena itu adalah bidang keahliannya. Namun, individu tersebut akan menolak jika diminta memainkan alat musik karena tidak pandai dalam memainkannya. Hal ini menjelaskan bahwa efikasi diri akan mendorong individu untuk menghargai dan menempatkan diri pada posisi yang tepat. Individu tahu di mana dan kapan harus mempertanggungjawabkan kemampuannya dengan baik.

Menurut Bandura (dalam Feist \& Feist, 2009) salah satu faktor yang mempengaruhi efikasi diri yaitu kondisi fisik dan emosional. Individu dengan emosi yang kuat dapat mengurangi performa individu tersebut, seperti saat mengalami ketakutan, kecemasan, atau stres yang tinggi. Hal ini dapat berdampak pada efikasi diri yang rendah. Individu yang mampu mengendalikan ketakutan, kecemasan dan stresnya tersebut akan mengakibatkan penurunan rasa cemas sehingga dapat meningkatkan performa individu yang berpengaruh terhadap efikasi diri. Penerimaan diri ketika menghadapi penderitaan dan situasi sulit dalam hidup disebut self-compassion.
Self-compassion merupakan cara adaptif untuk berhubungan dengan diri ketika menghadapi kekurangan pribadi atau keadaan hidup yang sulit (Neff \& McGehee, 2010). Self-compassion merupakan strategi untuk menangani emosi negatif dan dapat membebaskan diri dari siklus destruktif akibat reaksi emosi tersebut (Neff, 2011). Gabungan motif, emosi, pikiran, dan perilaku akan memunculkan compassion. Individu yang compassionate, memiliki kesadaran saat seseorang sedang dalam penderitaan, menghilangkan ketakutan terhadap hal tersebut, dan memberikan rasa cinta dan kasih sayang kepada individu yang sedang mengalami penderitaan. Hal ini selaras dengan penelitian Yarnell dan Neff (2013) yang menunjukkan hasil bahwa individu yang selfcompassionate akan menyelesaikan masalah dengan cara menyeimbangkan kebutuhan diri dan orang lain. Hal ini mencakup penerimaan terhadap individu, penderitaan yang dirasakan, dan reaksi terhadap penderitaan tersebut (Germer, 2009). Self-compassion mengharuskan individu untuk tidak menghindari atau menekan perasaan yang menyakitkan, sehingga individu dapat mengakui dan merasakan compassion untuk pengalamannya (Neff, 2003).

Berdasarkan paparan di atas, hipotesis dalam penelitian ini adalah terdapat hubungan positif yang signifikan antara self-compassion dan efikasi diri pada mahasiswa yang sedang menyelesaikan tugas akhir. Penelitian ini dilakukan pada mahasiswa semester 6 Fakultas Psikologi Universitas Y.

\section{Metode}

Subjek yang digunakan sebagai sampel penelitian adalah mahasiswa semester 6 Fakultas Psikologi Universitas Y berjumlah 110 orang. Teknik pengambilan sampel yang 
digunakan dalam penelitian ini adalah teknik simple random sampling.

Pengumpulan data dalam penelitian ini dilakukan dengan menggunakan dua skala yaitu Skala Self-Compassion yang memiliki 22 butir $(\alpha=0.858)$ dan disusun berdasarkan aspek-aspek self-compassion yaitu selfkindness, common humanity, dan mindfulness serta Skala Efikasi Diri yang memiliki 22 butir $(\alpha=0.850)$ yang disusun berdasarkan aspekaspek efikasi diri yaitu level atau besarnya, generality atau generalitas, dan strength atau kekuatan.

Berdasarkan hasil try out, Skala SelfCompassion menunjukkan koefisien reliabilitas sebesar 0.858 dengan jumlah butir valid sebanyak 22 butir dan hasil try out Skala Efikasi Diri menunjukkan koefisien reliabilitas sebesar 0.850 dengan butir valid sebanyak 22 butir. Berdasarkan hasil koefisien reliabilitas tersebut, kedua skala yang diunakan pada penelitian ini dapat dikategorikan handal. Menurut Azwar (2008), suatu alat ukur akan memiliki koefisien reliabilitas yang tinggi apabila koefisien reliabilitasnya semakin mendekati angka 1.00.

Teknik analisis data yang digunakan dalam penelitian ini adalah analisis regresi sederhana. Proses analisis data dalam penelitian ini dibantu dengan program komputer Statistical Package for Social Sciences (SPSS) 21 for Windows.

\section{Hasil}

Uji normalitas terhadap data yan diperoleh menunjukkan nilai KolmogorovSmirnov sebesar 0.812 dengan nilai signifikansi $\mathrm{p}=0.525$ ( $\mathrm{p}>0.05)$ untuk variabel efikasi diri dan nilai Kolmogorov-Smirnov sebesar 0.973 dengan nilai signifikansi $\mathrm{p}=0.301 \quad(\mathrm{p}>0.05) \quad$ untuk variabel self- compassion. Hasil tersebut menunjukkan bahwa variabel efikasi diri dan selfcompassion memiliki distribusi yang normal. Tabel 1 memberikan gambaran selengkapnya mengenai hasil uji normalitas pada data penelitian ini.

Tabel 1

Uji Normalitas

\begin{tabular}{lccc}
\hline Variabel & $\begin{array}{c}\text { Kolmogorov- } \\
\text { Smirnov }\end{array}$ & $\mathbf{p}>\mathbf{0 . 0 5}$ & Bentuk \\
\hline Efikasi diri & 0.812 & 0.525 & Normal \\
Self-compassion & 0.973 & 0.301 & Normal \\
\hline
\end{tabular}

Selain uji normalitas, dilakukan pula uji linearitas, dengan hasil yang menunjukkan bahwa hubungan antara variabel selfcompassion dan efikasi diri menghasilkan nilai koefisien $\mathrm{F}=131.453$ dengan nilai signifikansi $\mathrm{p}=0.000$. Hasil tersebut menunjukkan bahwa kedua variabel penelitian memiliki hubungan yang linear. Hasil uji linearitas selengkapnya dapat dilihat pada Tabel 2.

Tabel 2

Uji Linearitas

\begin{tabular}{lccc}
\hline $\begin{array}{c}\text { Hubungan } \\
\text { Variabel }\end{array}$ & Nilai F & $\begin{array}{c}\text { Signifikansi } \\
(\mathbf{p}<\mathbf{0 . 0 5})\end{array}$ & Keterangan \\
\hline $\begin{array}{l}\text { Self- } \\
\text { compassion } \\
\text { dengan }\end{array}$ & 131.453 & 0.000 & Linier \\
\begin{tabular}{l} 
Efikasi diri \\
\hline
\end{tabular}
\end{tabular}

\section{Uji hipotesis}

Hasil analisis regresi sederhana menunjukkan besarnya koefisien korelasi antara self-compassion dan efikasi diri adalah sebesar 0.741 dengan nilai signifikansi 0.000 $(\mathrm{p}<0.05)$. Koefisien korelasi dengan nilai positif menunjukkan bahwa arah hubungan antara self-compassion dan efikasi diri adalah positif. Hal ini dapat diartikan bahwa individu yang terkategori memiliki self-compassion maka individu tersebut memiliki efikasi diri. Tingkat signifikansi korelasi sebesar $\mathrm{p}=0.000$ 
$(\mathrm{p}<0.05)$ menunjukkan bahwa terdapat hubungan yang signifikan antara selfcompassion dan efikasi diri. Berdasarkan paparan di atas, dapat disimpulkan bahwa hipotesis yang diajukan dalam penelitian, yaitu ada hubungan positif yang signifikan antara self-compassion dan efikasi diri pada mahasiswa yang sedang menyelesaikan tugas akhir, dapat diterima.

Nilai koefisien determinan ( $R$ Square) sebagaimana dipaparkan pada Tabel 3 menunjukkan bahwa self-compassion memberikan sumbangan efektif sebesar $54.9 \%$ pada efikasi diri. Sisanya sebesar $45.1 \%$ ditentukan atau dipengaruhi oleh faktor-faktor lain yang tidak diungkap dalam penelitian.

Tabel 3

Koefisien Determinasi Self-Compassion Terhadap Efikasi Diri

\begin{tabular}{ccccc}
\hline Model & R & R Square & $\begin{array}{c}\text { Adjusted R } \\
\text { Square }\end{array}$ & $\begin{array}{c}\text { Std. Error of } \\
\text { the Estimate }\end{array}$ \\
\hline 1 & $.741 \mathrm{a}$ & .549 & .545 & 4.302 \\
\hline
\end{tabular}

Penelitian ini sesuai dengan Germer (2009) yang menyatakan bahwa selfcompassion adalah penerimaan diri ketika individu sedang mengalami penderitaan. Hal tersebut secara tidak langsung dapat mengurangi dampak dari peristiwa negatif dalam kehidupannya yang akan memunculkan keyakinan terhadap diri sendiri.

\section{Diskusi}

Penelitian ini bertujuan untuk mengetahui hubungan antara self-compassion dan efikasi diri pada mahasiswa yang sedang menyelesaikan tugas akhir. Berdasarkan hasil analisis, terlihat bahwa semakin tinggi selfcompassion maka semakin tinggi efikasi diri yang akan ditunjukkan mahasiswa yang sedang menyelesaikan tugas akhir. Hasil uji hipotesis tersebut menunjukkan angka koefisien korelasi sebesar 0.741 dengan signifikansi $0.000(\mathrm{p}<0.05)$. Koefisien korelasi dengan nilai positif menunjukkan bahwa arah hubungan antara self-compassion dan efikasi diri adalah positif. Tingkat signifikansi sebesar $\mathrm{p}=0.000$ menunjukkan adanya hubungan yang signifikan antara self-compassion dan efikasi diri pada mahasiswa yang sedang menyelesaikan tugas akhir.

Penelitian ini sesuai dengan penelitian eksperimen Smeets, Neff, Alberts, dan Peters (2014) yang dilakukan terhadap 52 orang mahasiswi yang dibagi ke dalam dua kelompok dan salah satu kelompok diberikan intervensi self-compassion. Hasil studi mereka menunjukkan bahwa program intervensi selfcompassion yang singkat dapat meningkatkan resiliensi dan well-being secara efektif bagi mahasiswi. Selain itu, program intervensi selfcompassion juga dapat membantu mahasiswi menghadapi tantangan dalam kehidupan di universitas, karena program ini dapat meningkatkan kepercayaan diri partisipan dalam menghadapi situasi yang menantang.

Mahasiswa Fakultas Psikologi semester 6 yang sedang menyelesaikan tugas akhir dalam penelitian ini mayoritas memiliki selfcompassion yang tinggi. Hal ini menunjukkan bahwa mahasiswa mampu menghadapi tantangan dalam hidupnya, salah satunya tantangan dalam menyelesaikan skripsi. Germer (2009) menyatakan bahwa selfcompassion adalah penerimaan diri ketika individu sedang mengalami penderitaan. Hal tersebut selaras dengan penelitian yang dilakukan oleh Lutz, Greischar, Rawlings, Ricard, dan Davidson (2004) yang menyatakan bahwa perasaan compassion terhadap diri sendiri dan orang lain berhubungan dengan tingkat aktivasi otak yang lebih tinggi pada prefrontal korteks bagian kiri, yaitu bagian 
yang berhubungan dengan kebahagiaan dan optimisme. Secara tidak langsung, individu dengan self-compassion dapat mengurangi dampak dari peristiwa negatif dalam kehidupannya yang akan memunculkan keyakinan terhadap diri sendiri.

Penelitian lain yang dilakukan oleh Neff, Rude, dan Kirkpatrick (2007) menunjukkan bahwa individu dengan self-compassion secara signifikan mengalami suasana hati yang positif dan hanya merasakan sedikit suasana hati negatif yang wajar. Hal ini dikarenakan selfcompassion dapat mengurangi reaksi maladaptif individu terhadap peristiwa negatif (Germer \& Neff, 2013), sehingga keyakinan individu terhadap dirinya lebih terlihat.

Efikasi diri sebagai keyakinan individu akan mengacu pada keyakinan pribadi mengenai kompetensi diri terhadap kemampuan untuk menyelesaikan suatu tugas secara berhasil (Ivancevich, Konopaske, \& Matteson, 2006). Seseorang melakukan suatu pekerjaan atau berusaha untuk memenuhi tujuan tertentu sangat bergantung pada keyakinannya akan berhasil dalam melakukan tindakan tersebut (Fiske \& Taylor, 2008).

Berdasarkan analisis data yang telah dilakukan, hasil penelitian ini menunjukkan bahwa self-compassion memberikan sumbangan efektif sebesar $54.9 \%$ pada efikasi diri. Sisanya sebesar $45.1 \%$ ditentukan atau dipengaruhi oleh faktor-faktor lain yang tidak diungkap dalam penelitian.

Berdasarkan hasil penelitian, dapat ditarik kesimpulan bahwa hipotesis yang diajukan peneliti yaitu ada hubungan positif yang signifikan antara self-compassion dan efikasi diri pada mahasiswa yang sedang menyelesaikan tugas akhir dapat diterima. Dengan kata lain, efikasi diri dapat diprediksi dari variabel self-compassion. Saran untuk penelitian selanjutnya antara lain diharapkan agar memperhatikan kalimat-kalimat pada butir yang akan digunakan dalam penyusunan Skala Efikasi Diri maupun Skala SelfCompassion agar hasilnya lebih mengungkap secara maksimal dan disarankan untuk memperhatikan faktor-faktor lain yang mungkin mempengaruhi efikasi diri, misalnya persuasi sosial, pemodelan sosial, pengalaman hidup, dan perasaan atau aspek emosional.

\section{Daftar Pustaka}

Ali, M., \& Asrori, M. (2008). Psikologi Remaja Perkembangan Peserta Didik. Jakarta: Bumi Aksara.

Alwisol. (2009). Psikologi Kepribadian. Malang: UMM Press.

Azwar, S. (2008). Penyusunan Skala Psikologi. Yogyakarta: Pustaka Pelajar.

Baron, R. A., \& Byrne, D. (2004). Psikologi Sosial Edisi Kesepuluh Jilid 1. Jakarta: Erlangga.

Chemers, M. M., Hu, L. T., \& Garcia, B. F. (2001). Academic self-efficacy and firstyear college student performance and adjustment. Journal of Educational Psychology, 93(1), 55-64.

Dariyo, A. (2004). Psikologi Perkembangan Remaja. Bogor: Ghalia Indonesia.

Feist, J., \& Feist. G. J. (2009). Teori Kepribadian Buku 2 Edisi 7. Jakarta: Salemba Humanika.

Fiske, S. T., \& Taylor, S. E. (2008). Social Cognition from Brains to Culture. Newyork: McGraw-Hill.

Germer, C. K. (2009). The Mindful Path to Self-Compassion: Freeing Yourself from 
Destructive Thoughts and Emotions. New York: The Guilford Press.

Germer, C. K., \& Neff, K. D. (2013). Selfcompassion in clinical practice. Journal of Clinical Psychology: In Session, 69(8), 856-867. doi:10.1002/jclp.22021.

Ivancevich, J. M., Konopaske, R., \& Matteson, M. T. (2006). Perilaku dan Manajemen Organisasi Jilid 1. Jakarta: Erlangga.

Lutz, A., Greischar, L. L., Rawlings, N. B., Ricard, M., \& Davidson, R. J. (2004). Long-term meditators self-induce highamplitude gamma synchrony during mental practice. Proceeding of the National Academy of Sciences of the United States of America, 101(46), 16369-16373.

doi:10.1073/pnas.0407401101.

Neff, K. D. (2003). Self-compassion: an alternative conceptualization of a healthy attitude toward oneself. Self and Identity, 2, 85-101.

Neff, K. D. (2011). Self-Compassion: Stop Beating Yourself $U p$ and Leave Insecurity Behind. London: Hodder and Stoughton.

Neff, K. D., \& McGehee, P. (2010). Selfcompassion and psychological resilience among adolescents and young adults. Self and Identity, 9(3), 225-240.

Neff, K. D., Rude, S. S., \& Kirkpatrick, K. L. (2007). An examination of selfcompassion in relation to positive psychological functioning and personality traits. Journal of Research in Personality, 41(4), 908-916. doi:10.1016/j.jrp.2006.08.002.

Santrock, J. W. (2007). Remaja Edisi Kesebelas Jilid 2. Jakarta: Erlangga.
Santrock, J. W. (2012). Life-Span Development: Perkembangan MasaHidup Edisi Ketiga Belas Jilid 1. Jakarta: Erlangga.

Smeets, E., Neff, K., Alberts, H., \& Peters, M. (2014). Meeting suffering with kindness: effect of a brief of self-compassion intervention for female college students. Journal of Clinical Psychology, 70(9), 794-807. doi:10.1002/jclp.22076.

Widanarti, N., \& Indati, A. (2002). Hubungan antara dukungan sosial keluarga dengan self-efficacy pada remaja di SMU Negeri 9 Yogyakarta. Jurnal Psikologi, 29(2), 112-123.

Yarnell, L. M., \& Neff, K. D. (2013). Selfcompassion, interpersonal conflict resolutions, and well-being. Self and Identity, $\quad 12, \quad 146-159$. http://dx.doi.org/10.1080/15298868.201 1.649545 . 